\title{
Centimeters of Mercury
}

National Cancer Institute

\section{Source}

National Cancer Institute. Centimeters of Mercury. NCI Thesaurus. Code C147129.

A unit of pressure equal to 0.001316 atmosphere and equal to the pressure indicated by one centimeter rise of mercury in a barometer at the Earth's surface. 